\title{
ALK Rearrangement in Anaplastic Thyroid Carcinoma: A Discovery Towards a Personalized Approach?
}

\section{Eivind Blais ${ }^{*}$, Axelle Dutertre and Yann Godbert}

Thyroid Group, Institut Bergonie, 229 Cours de I'Argonne, 33000 Bordeaux, France

*Corresponding author: Eivind Blais, Thyroid Group, Institut Bergonie, 229 Cours de l'Argonne, 33000 Bordeaux, France, Tel: 335563333 33; E-mail: eivind.blais@hotmail.fr

Received date: Dec 18, 2015, Accepted date: Jan 07, 2016, Publication date: Jan 11, 2016

Copyright: (c) 2016 Blais E, et al. This is an open-access article distributed under the terms of the Creative Commons Attribution License; which permits unrestricted use; distribution; and reproduction in any medium; provided the original author and source are credited.

Anaplastic thyroid carcinoma (ATC) represents about $1 \%$ of all thyroid carcinomas [1]. ATC is the most aggressive form of thyroid carcinoma especially when metastatic - accounting for $14-50 \%$ of all thyroid cancer related deaths [2]. Prognosis and outcomes following local progression or metastasis are poor using conventional therapies such as surgery, chemotherapy, and external beam radiation therapy with only $20 \%$ survival at 1 year [3]. So far, previous attempts to use multi-target tyrosine kinase inhibitors have not improved survival outcomes [4]. Therefore, molecular screening for specific genetic alterations in ATC tumors may provide an opportunity for an efficient, targeted therapy.

In recent years, the discovery of a variety of molecular and genetic alterations in different malignancies leading to oncogenesis has provided an insight into the complexity of tumorigenesis. This information can be used to target specific markers with the objective of improving patient outcomes. Yoshihara et al. described potentially 'druggable' kinase fusions in $8.7 \%$ of thyroid carcinomas [5]. The anaplastic lymphoma kinase (ALK) TK receptor (TKR) has recently emerged as a potentially relevant biomarker and a therapeutic target in solid and hematologic tumors. The ALK TKR gene is located at $2 \mathrm{p} 23.2$ and belongs to the insulin receptor superfamily [6]. A variety of alterations in the ALK gene such as mutations, overexpression, amplification, translocations, or other structural rearrangements have been implicated in tumorigenesis [7]. Hamatani et al. reported that, in 10 out of 19 papillary thyroid cancer (PTC) cases, ALK rearrangements are involved in the development of radiation-induced adult-onset PTC [8]. Demeure et al. identified an EML4-ALK translocation as the driver of PTC [9].

We previously reported the identification of a recurrent StriatinALK (STRN-ALK) fusion - the result of a complex rearrangement involving the short arm of chromosome 2 - in thyroid carcinomas [10]. Kelly et al. showed that STRN-ALK fusion occurred with a higher prevalence in poorly-differentiated ATCs without other overlapping known driver mutations in these tumors [11]. These data demonstrate that STRN-ALK fusion occurs in a subset of patients with highly aggressive types of thyroid cancer and could be a potential therapeutic target in these patients

These recent reports also highlight the potential use of drugs such as crizotinib that target ALK rearrangement with proven efficiency in non-small cell lung carcinomas [12] for highly aggressive types of thyroid cancer. We previously described a remarkable response to crizotinib in a 71-year-old woman suffering from a chemoresistant ATC with lung metastases. Three months after the initiation of crizotinib, an exceptional response of more than $90 \%$ across all pulmonary lesions was observed [13]. The patient is still alive two years after the introduction of crizotinib. CT evaluation has shown a complete response and the treatment has been well tolerated without any grade 2 or higher adverse effect.

This encouraging outcome aside, the prevalence of ALK rearrangements in ATC and poorly-differentiated thyroid tumors still remains unknown emphasizing the need for such studies. Currently, a multi-institutional French study is evaluating the prevalence of ALKrearrangements $(\mathrm{ALK}+)$ in ATC (Tuthyref network). At present, the methods to detect the different molecular alterations of ALK1 gene are limited to immunohistochemistry, fluorescence in situ hybridization (FISH) and reverse transcriptase PCR methods. Further efforts are warranted to determine the optimal, cost-effective method for routine diagnostic detection of ALK fusions in thyroid cancers.

In our previous case report, using FISH, an ALK rearrangement was identified in more than $50 \%$ of cells in the various components of the tumor (well-differentiated and ATC components as well as in a lung metastasis). Nevertheless, establishing the best percentage cut-off for ALK+ tumor cells, as determined by FISH, for deciding the introduction of a drug targeting ALK-rearrangement remains a challenge. Currently, a phase II multi-institutional study to evaluate crizonitib's efficacy in ATC ALK+ tumors is ongoing in France. Rare neoplasia with poor outcomes, such as ATC could be interesting to identify potential targets for new drugs based on molecular screening of gene alterations.

\section{References}

1. Sherman SI (2003) Thyroid carcinoma. Lancet 361: 501-511.

2. Nagaiah G, Hossain A, Mooney CJ, Parmentier J, Remick SC (2011) Anaplastic thyroid cancer: a review of epidemiology, pathogenesis, and treatment. J Oncol: 542358.

3. Kebebew E, Greenspan FS, Clark OH, Woeber KA, McMillan A (2005) Anaplastic thyroid carcinoma. Treatment outcome and prognostic factors. Cancer 103:1330-1335.

4. Savvides P, Nagaiah G, Lavertu P, Fu P, Wright JJ, et al.( 2013) Phase II trial of sorafenib in patients with advanced anaplastic carcinoma of the thyroid. Thyroid 23: 600-604.

5. Yoshihara K, Wang Q, Torres-Garcia W, Zheng S, Vegesna R, et al. (2015) The landscape and therapeutic relevance of cancer-associated transcript fusions. Oncogene 34: 4845-4854.

6. Morris SW, Kirstein MN, Valentine MB, Dittmer KG, Shapiro DN, et al. (1994) Fusion of a kinase gene, ALK, to a nucleolar protein gene, NPM, in non-Hodgkin's lymphoma. Science 263: 1281-1284.

7. Grande E, Bolos M-V, Arriola E (2011) Targeting oncogenic ALK: a promising strategy for cancer treatment. Mol Cancer Ther: 569-579.

8. Hamatani K, Mukai M, Takahashi K, Hayashi Y, Nakachi K, et al. (2012) Rearranged anaplastic lymphoma kinase (ALK) gene in adult-onset 
Citation: Blais E, Dutertre A, Godbert Y (2016) ALK Rearrangement in Anaplastic Thyroid Carcinoma: A Discovery Towards a Personalized Approach?. J Nucl Med Radiat Ther 7: 275. doi:10.4172/2155-9619.1000275

Page 2 of 2

papillary thyroid cancer amongst atomic bomb survivors. Thyroid 22: 1153-1159.

9. Demeure MJ, Aziz M, Rosenberg R, Gurley SD, Bussey KJ, et al. (2014) Whole-genome sequencing of an aggressive BRAF wild-type papillary thyroid cancer identified EML4-ALK translocation as a therapeutic target. World J Surg 38: 1296-1305.

10. Perot G, Soubeyran I, Ribeiro A, Bonhomme B, Savagner F, et al. (2014) Identification of a recurrent STRN/ALK fusion in thyroid carcinomas. PLoSONE: 87170.

11. Kelly LM, Barila G, Liu P, Evdokimova VN, Trivedi S, et al. (2014) Identification of the transforming STRN-ALK fusion as a potential therapeutic target in the aggressive forms of thyroid cancer. Proc Natl Acad Sci USA 111: 4233-4238.

12. Solomon BJ, Mok T, Kim D-W, Wu Y-L, Nakagawa K, et al. (2014) First-line crizotinib versus chemotherapy in ALK-positive lung cancer. N Engl J Med 371: 2167-2177.

13. Godbert Y, Henriques de Figueiredo B, Bonichon F, Chibon F, Hostein I, et al. (2015) Remarkable Response to Crizotinib in Woman With Anaplastic Lymphoma Kinase-Rearranged Anaplastic Thyroid Carcinoma. J Clin Oncol 33: 84-87. 